\title{
GESTIÓN DE RECURSOS LÍTICOS Y ORGANIZACIÓN ESPACIAL DE CAZADORES RECOLECTORES EN LA ESTEPA DE LOS VALLES DE CISNES Y SIMPSON, REGIÓN DE AYSÉN, CHILE
}

\author{
CATALINA CONTRERAS ${ }^{a}$, CÉSAR MÉNDEZ ${ }^{b} \&$ OMAR REYES ${ }^{c}$
}

\begin{abstract}
RESUMEN
Se presenta un análisis comparativo de las ocupaciones de cazadores recolectores en los sectores estepáricos altos de dos valles de la región de Aysén, correspondientes a las cuencas de los ríos Simpson y Cisnes. El estudio se basa en el análisis de materiales líticos hallados en sitios superficiales a cielo abierto. Se evalúan las características tecnológicas y la función de los conjuntos líticos mencionados y se consideran las reconstrucciones ambientales disponibles para ambos sectores. Se discute el aprovechamiento y gestión de los recursos líticos que conforman la oferta local, para dar luces respecto de la organización espacial de los grupos humanos que ocuparon estos espacios durante el Holoceno tardío.
\end{abstract}

PALABRAS CLAVE: tecnología lítica, gestión de recursos, organización espacial.

\section{LITHIC RESOURCE MANAGEMENT AND SPATIAL ORGANIZATION \\ OF HUNTER-GATHERERS IN THE STEPPE OF CISNES AND SIMPSON VALLEYS, AYSÉN REGION, CHILE}

\begin{abstract}
We present a comparative analysis of hunter-gatherer occupations at the upper steppe portions of two valleys in the Aysén region, namely the Simpson and Cisnes basins. The study is based on the analysis of lithic materials located in the surface of open-air sites. We assess the technological characteristics and the function of the lithic assemblages and consider the available environmental reconstructions for each zone. The paper discusses the use and management of local lithic resources, in order to shed light on the spatial organization of the groups that occupied these areas during the late Holocene.

KEY WORDS: lithic technology, resource management, spatial organization.

a PhD Candidate. Institute of Archaeology, University College London. 31-34 Gordon Square, London WC1H 0PY, United Kingdom. catalina.contreras.mira@gmail.com

b Departamento de Antropología, Facultad de Ciencias Sociales, Universidad de Chile. C. Ignacio Carrera Pinto 1045, Nuñoa, Santiago, Chile. cmendezm@uchile.cl

c Centro de Estudios del Hombre Austral, Instituto de la Patagonia, Universidad de Magallanes. Av. Bulnes 01890, Punta

Arenas, Chile. omarreyesbaez@gmail.com
\end{abstract}




\section{INTRODUCCIÓN}

A lo largo de su historia, la región de Aysén fue invariablemente habitada por sociedades cazadoras-recolectoras y sus planicies esteparias presentan en la actualidad un medio ambiente $y$ un esquema de recursos comparables en toda su extensión. No obstante, resulta necesario evaluar si esta homogeneidad posee un correlato a nivel arqueológico, ya que estudios paleoambientales han permitido reconocer una mayor diversidad de ambientes y distribución de recursos en el pasado en la escala de milenios (De Porras et al. 2012 , 2014). Este trabajo se enfoca en la relación existente entre la disponibilidad de recursos líticos y su gestión, en tanto son indicadoras de la organización tecnológica y espacial de los cazadores recolectores (Odell, 2003). Para ello, nuestra investigación se centró en las cabeceras de dos valles extra-andinos del centro-norte de Aysén:

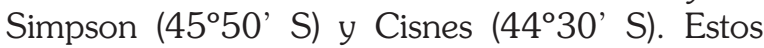
valles son significativos por las notables diferencias que presentan los conjuntos líticos recuperados en ellos y que serán analizadas en este artículo.

La evidencia humana más temprana en la región de Aysén, corresponde a la del sitio El Chueco 1, en la cabecera del valle del río Cisnes, fechada en $\sim 11.500$ años cal AP y sería evidencia de la ocupación efímera de este reparo (Reyes et al. 2007). En este sitio, así como en Baño Nuevo-1, en el cercano valle del río Nirehuao, las evidencias para el Holoceno temprano se vuelven más recurrentes (Mena \& Stafford, 2006; Méndez et al. 2011a; Reyes et al. 2012). Ambos sitios muestran haber sido ocupados interrumpidamente hasta avanzado el Holoceno tardío (Méndez et al. 2011a), periodo durante el cual las ocupaciones humanas no sólo se registran en locaciones en los planos esteparios orientales, sino que se reconocen en distintos ambientes, como ha sido propuesto para la cuenca del río Cisnes (Méndez \& Reyes, 2008). El advenimiento de condiciones áridas hacia los $3.000 \mathrm{cal}$ AP ha sido reconocido como un potencial factor en la reconfiguración de las estrategias de asentamiento (Reyes et al. 2009; De Porras et al. 2012, 2014). Para el Holoceno Tardío se reconoce una mayor intensidad en el uso del espacio en esta región, lo que ha sido observado en el mayor número y distribución de los asentamientos habitacionales $y$ funerarios (chenques) y corroborado por las edades ${ }^{14} \mathrm{C}$ y de termoluminiscencia y la comparación de características tecno-tipológicas de piezas clave (Mena, 2000; Mena \& Lucero, 2004; Reyes et al. 2006; Méndez \& Reyes, 2008). Este periodo es notoriamente el más estudiado y del cual ha sido posible recuperar más evidencias, provenientes tanto de sitios bajo reparo rocoso como a cielo abierto.

\section{ÁREA DE ESTUDIO}

La región de Aysén, con alrededor de $110.000 \mathrm{~km}^{2}$, exhibe longitudinalmente una gradiente bioecológica muy abrupta, al incluir desde los archipiélagos y canales boscosos del Pacífico, hasta las planicies esteparias ubicadas inmediatamente al oriente de los Andes. Estos espacios son accesibles gracias a la presencia de valles que interrumpen esta gradiente (Mena, 2000, p. 21). Para efectos de esta investigación, estudiaremos las cabeceras orientales de dos de estos valles, correspondientes a los sectores altos de las cuencas de los ríos Cisnes y Simpson, norte de Aysén (Fig. 1).

El área de estudio corresponde a los Relieves Planiformes Orientales (720-940 msnm), los cuales se presentan como planos depositacionales bordeados por amplios lomajes, interrumpidos por geoformas de origen glaciar (Prieto et al. 1994).

Este sector es parte de la Ecorregión Estepárica Fría de la Patagonia Oriental (SERPLAC, 2005), donde el clima se caracteriza por bajas temperaturas, veranos ventosos $y$ fríos inviernos. Debido a su ubicación al este de los Andes, las precipitaciones del Cinturón de Vientos del Oeste son condicionadas por el efecto orográfico (Garreaud, 2009). Éstas alcanzan los $584 \mathrm{~mm}$ anuales en la ciudad de Balmaceda, en Alto Simpson, mientras que en Alto Cisnes son cercanas a los $436 \mathrm{~mm}$ anuales (Quintanilla, 1983). Las formaciones vegetacionales se reconocen como de estepa mediterráneatemplada de Festuca pallescens y Mulinum spinusum de carácter xerófito, la cual destaca por presentar una fisonomía homogénea de poáceas y arbustos bajos (Luebert \& Pliscoff, 2006). Estos son elementos dominantes en superficies llanas, 


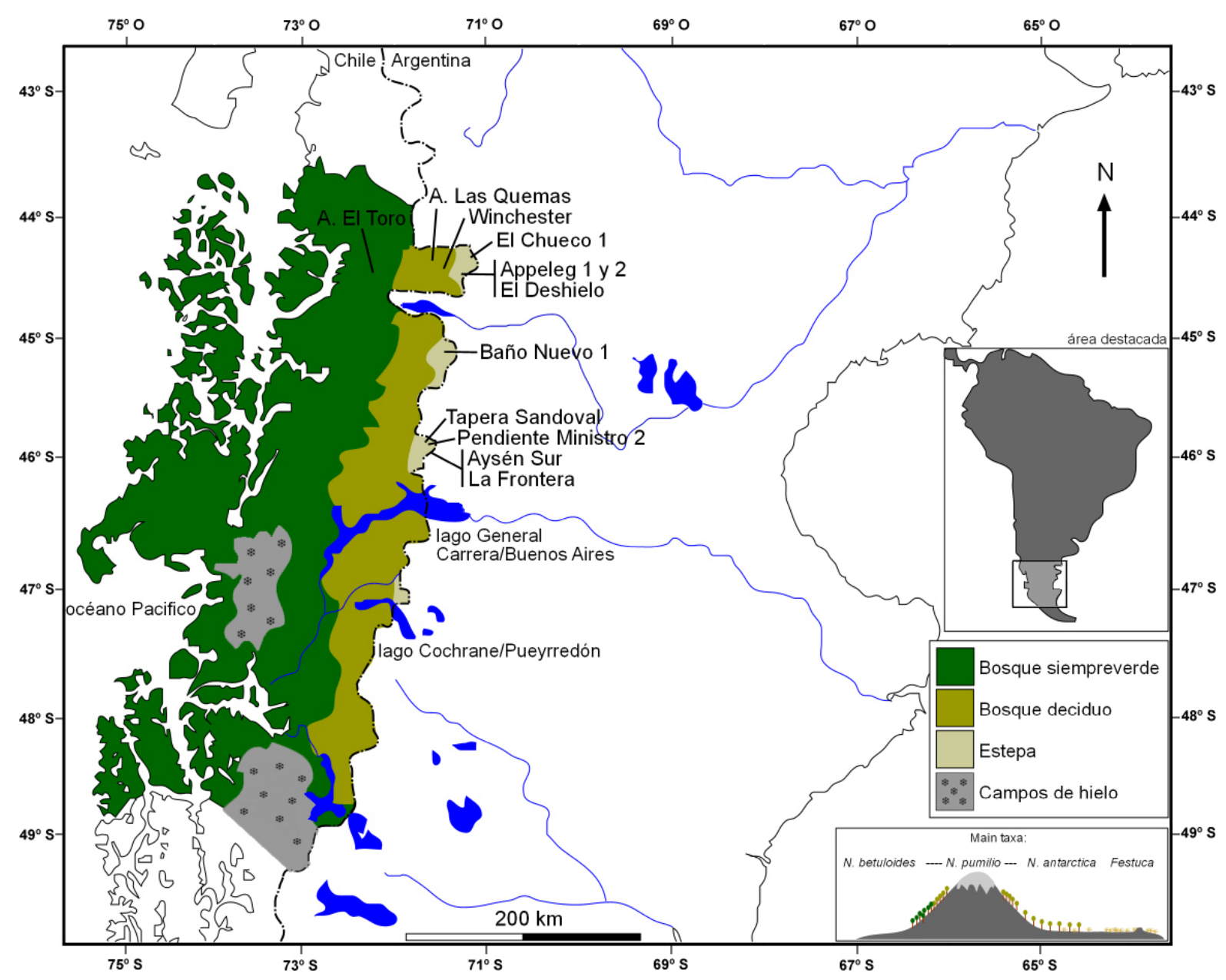

Fig. 1. Mapa de la región de Aysén con distribuciones fitogeográficas y áreas de interés destacadas.

mientras que en condiciones de mayor altitud o humedad se observan matorrales altos y parches de bosques deciduos de lenga (Nothofagus pumilio) y ñire (Nothofagus antartica) (Luebert \& Pliscoff, 2006).

Hoy sabemos, sin embargo, que lo que hoy reconocemos como estepa abierta y transición bosque estepa en Aysén ha sido reducido por la acción antropogénica. Desde comienzos del siglo XX, grandes incendios provocados por la colonización ganadera modificaron radicalmente la extensión del bosque (Martinic, 2005). Este retrocedió y la estepa fue ganando territorio en algunos sectores, lo que incentivó la erosión y el arrastre de sedimentos desde las laderas. Este proceso ha sido esgrimido como una posible alternativa para entender la diferencial distribución de materiales en superficie el Alto río Simpson al compararlo con otros sectores de estepa menos afectos a ello (Méndez et al. 2013). La erosión probablemente generó altas tasas de depositación sedimentaria en los planos, lo cual puede haber enterrado más activamente los restos arqueológicos. En consecuencia, si bien decidimos comparar el registro arqueológico de Alto Simpson y Alto Cisnes, entendemos que las modificaciones históricas del entorno podrían estar incidiendo en nuestra actual observación de las características ambientales, las cuales pudieron ser diferentes en los milenios anteriores a la presencia humana occidental. Esto no sólo tuvo consecuencias en la distribución de sus recursos y condiciones de habitabilidad, sino en la actual capacidad que tenemos para observar en superficies más abiertas". 


\section{MATERIAL Y MÉTODO}

De acuerdo con los objetivos de esta investigación, la escala analítica fue establecida a nivel de valle. Para el estudio de éstos, fueron realizadas prospecciones pedestres en sectores proporcionales, los que fueron estratificados a partir de características cualitativas, tales como cercanía a cursos de agua, rasgos del relieve e hitos geográficos (tales como cerros y bloques erráticos, entre otros) (Tabla 1). Los sectores fueron delimitados mediante cuadrantes de 1 $\mathrm{km}^{2}$ siguiendo coordenadas UTM, dentro de los cuales se establecieron transectas (se pueden encontrar mapas que muestran los cuadrantes de prospección en Méndez et al. 2013; Reyes et al. 2006). A esto se sumaron prospecciones dirigidas, enfocadas en hitos geográficos llamativos o lugares cuyas características proporcionaban condiciones propicias para el asentamiento. Tanto los sitios arqueológicos como los hallazgos aislados fueron geoposicionados, lo que fue aprovechado para definir la distribución espacial de algunas concentraciones dentro de los sitios más destacados (Reyes et al. 2006; Velázquez et al. 2007). El área prospectada alcanzó una superficie de $54 \mathrm{~km}^{2}$ en Alto Simpson y de $90 \mathrm{~km}^{2}$ en Alto Cisnes (Méndez et al. 2013; Reyes et al. 2006).

Los materiales recuperados fueron sometidos a diversas clases de análisis para determinar sus características tecnológicas y morfofuncionales.
Se realizó una caracterización morfofuncional de las categorías artefactuales presentes, siguiendo los métodos clasificatorios de Aschero (1983) y Jackson (2002). Las categorías fueron descritas basándose en criterios funcionales, morfológicos, tecnológicos, métricos y petrográficos (Jackson 2002, pp. 28-29).

Para esta etapa del análisis, los atributos de los artefactos que fueron considerados corresponden a fractura de la pieza y tipo de matriz y para los instrumentos, se consideran además la formatización (Andrefsky, 1994) y la clasificación tecnomorfológica. Se realizó también un análisis tecnológico de las piezas (Andrefsky, 1998) y para ello se registró otra serie de variables, como presencia de aristas paralelas, presencia de corteza y técnica de extracción.

Los atributos analizados sirvieron para definir la representación de etapas de la cadena operativa presentes en los conjuntos, según criterios que incluyen desde la clasificación tecnomorfológica de los artefactos, hasta el porcentaje de corteza que éstos posean. El estudio de las cadenas operativas supone el análisis de los desechos, derivados de núcleo, núcleos e instrumentos, en consideración con el rol que juegan en la secuencia de talla, ya que representan a las actividades que conforman el proceso de manufactura de instrumental lítico, es decir la obtención de matrices, el desbaste de guijarros y el procesamiento de los núcleos, la elaboración de instrumentos, el retoque y el

Tabla 1. Caracterización de los sitios mencionados.

\begin{tabular}{|c|c|c|c|c|c|c|}
\hline Sector & Sitio & $\begin{array}{l}\text { Unidades de } \\
\text { Concentración }\end{array}$ & Área $\left(m^{2}\right)$ & Altitud (msnm) & Geoforma & \# Líticos \\
\hline \multirow{4}{*}{ Cisnes } & 37 unidades y sitios & & $\begin{array}{l}6.379 \text { (ds: } \\
28.348)\end{array}$ & 809 (ds: 133) & & 1.259 \\
\hline & Appeleg 1 & 49 & 145.000 & 902 & $\begin{array}{c}\text { Médano } \\
\text { deflacionado }\end{array}$ & 1.093 \\
\hline & Appeleg 2 & 1 & 10.000 & 915 & $\begin{array}{c}\text { Médano } \\
\text { deflacionado }\end{array}$ & 99 \\
\hline & El Deshielo & 2 & 2.200 & & $\begin{array}{c}\text { Médano } \\
\text { deflacionado }\end{array}$ & 67 \\
\hline \multirow{5}{*}{ Simpson } & 13 sitios & & $\mathrm{S} / \mathrm{D}$ & 610 (ds: 92) & & 102 \\
\hline & Tapera Sandoval & 1 & 400 & 492 & $\begin{array}{c}\text { Médano } \\
\text { deflacionado }\end{array}$ & 10 \\
\hline & La Frontera & 1 & 600 & 676 & Ladera & 17 \\
\hline & Aysén Sur & 1 & 600 & 660 & Ladera & 7 \\
\hline & Pendiente Ministro 2 & 1 & 800 & 560 & Terraza fluvial & 9 \\
\hline
\end{tabular}




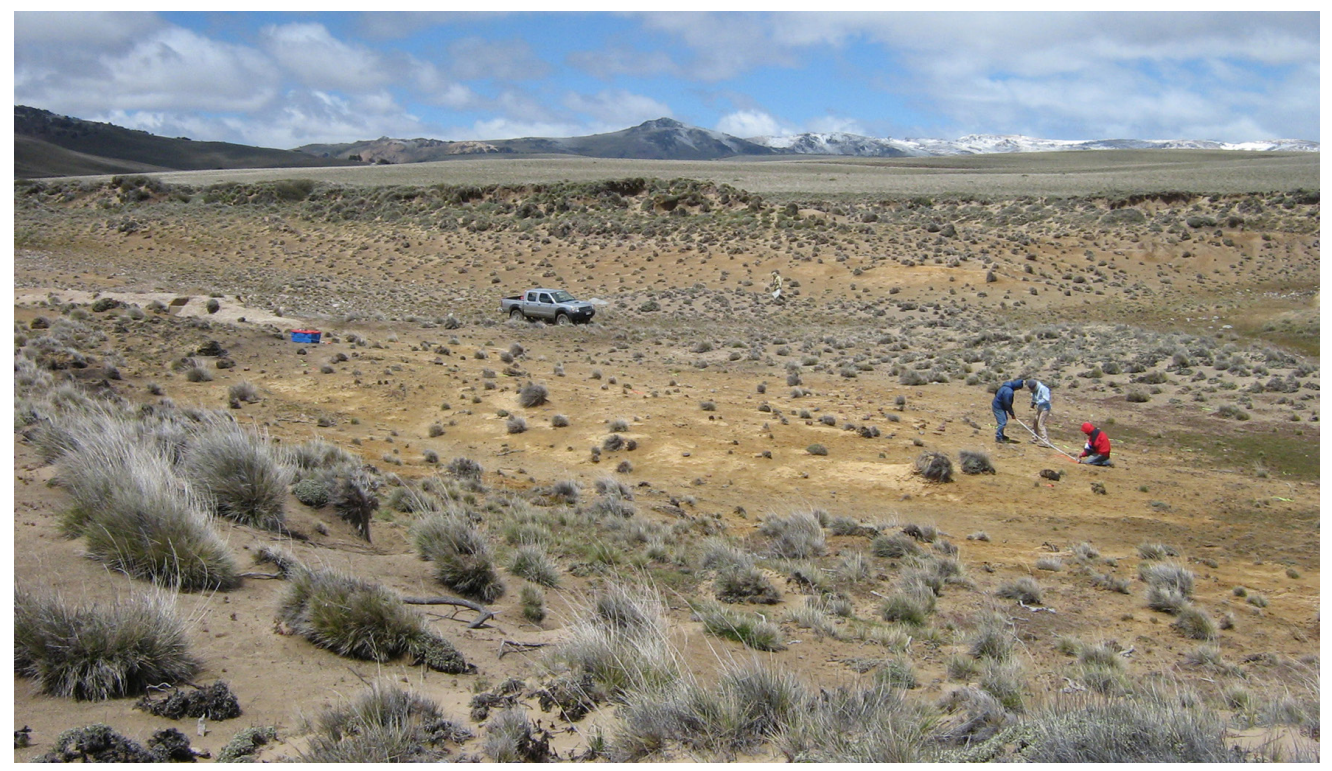

Fig. 2. Vista del sitio El Deshielo.

reavivado de los filos. En consecuencia, todas las categorías mencionadas cobran importancia, al ser piezas claves en la comprensión de los procesos tecnológicos que tuvieron lugar en los sitios arqueológicos en estudio.

La totalidad de los materiales provienen de contextos superficiales, ya sean sitios a cielo abierto o hallazgos aislados. En relación al sector de Alto Cisnes, fueron seleccionados los materiales provenientes los sitios Appeleg 1 y 2 y El Deshielo (CIS 009, CIS 018 y CIS 008, respectivamente) (Fig. 2), sumando 801 piezas líticas completas en total. En el caso de Alto Simpson, al ser una muestra muy reducida (Méndez et al. 2013), la totalidad de sitios $(\mathrm{N}=13)$ y hallazgos aislados $(\mathrm{N}=20)$ fueron incluidos en la muestra, totalizando ésta 75 piezas completas. Criterios tipológicos, asociaciones y características contextuales hacen presumir que estos conjuntos corresponden laxamente al Holoceno tardío. Sin embargo, la imposibilidad de atribuir una cronología absoluta a los conjuntos artefactuales recuperados indica que es necesario mantener esta sugerencia como hipótesis. Algunas características del sitio El Deshielo (su reducido tamaño, la significativa similitud tecnológica entre sus materiales y la uniformidad de las categorías morfofuncionales observadas) nos sugieren que corresponde a una sola ocupación, pese a que debido a las características del lugar donde se emplaza, es posible que haya sufrido procesos de coadunación de distintas ocupaciones. En contraste, Appeleg 1 es un conjunto multicomponente, que sería resultado de múltiples ocupaciones diacrónicas, ya que el sitio es mucho más extenso y presenta una amplia variabilidad de categorías artefactuales. El sitio representaría un conjunto superficial promediado (Borrero, 1994-1995), como sugiere el hallazgo de piezas de tipología temprana (Jackson \& Méndez, 2007) y también artefactos históricos como metales y vidrios (Velásquez et al. 2007). Existen dos

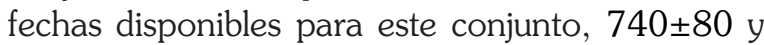
$1.290 \pm 130$ años AP. En el caso de Appeleg 2, la baja frecuencia de materiales permite suponer, al igual que en El Deshielo, que correspondería a los restos materiales de una sola ocupación, posiblemente tardía (Méndez et al. 2006). En Alto Simpson la situación se vuelve más compleja, ya que el reducido conjunto no incluye instrumentos diagnósticos que nos permitan sugerir con un cierto grado de certeza una cronología y la ausencia de material arqueológico en estratigrafía ha impedido la realización de fechados en los sitios encontrados.

Al tratarse de sitios superficiales, debemos ser cuidadosos al evaluar el efecto de procesos postdepositacionales en las características que presentan los sitios en la actualidad, ya que estos pueden haber afectado la preservación y las condiciones de visibilidad de los materiales. 


\section{RESULTADOS}

Cadenas operativas y aprovechamiento de materias primas líticas en Alto río Simpson

En el conjunto arqueológico correspondiente a Alto Simpson están caracterizadas todas las etapas de la secuencia de reducción lítica, aunque en ningún sitio arqueológico se encontró evidencias de cadenas operativas completas de una materia prima determinada (Tabla 2). De 102 artefactos hallados en los sitios, sólo 75 se encontraban completos y son incluidos en este análisis. Un $16 \%$ de ellos corresponde a núcleos, un 25,3\% a desechos de toda clase, un $32 \%$ a derivados de núcleo y un $26,6 \%$ a productos terminados.

En cuanto a las materias primas, en el sector de Alto Simpson, aprovecharon rocas de

Tabla 2. Segmento de la cadena operativa según materias primas, en los sitios de Alto Simpson.

\begin{tabular}{cccccc}
\hline $\begin{array}{c}\text { Materia prima por } \\
\text { sitio }\end{array}$ & $\begin{array}{c}\text { Derivados } \\
\text { de núcleo }\end{array}$ & Desechos & Núcleos & $\begin{array}{c}\text { Productos } \\
\text { terminados }\end{array}$ & $\begin{array}{c}\text { Total } \\
\text { general }\end{array}$ \\
\hline Aysén Sur & 5 & & 1 & & 6 \\
Andesita & 1 & & & & 1 \\
Dacita & 3 & & 1 & & 4 \\
Sílice & 1 & & & & 1 \\
\hline La Frontera & 2 & 5 & 4 & 3 & 14 \\
Andesita & & 1 & & 2 & 3 \\
Basalto & & 1 & & & 1 \\
Dacita & 2 & 2 & 2 & 1 & 7 \\
Riolita & & & 1 & & 1 \\
Sílice & & 1 & & & 1 \\
Toba & & & 1 & & 1 \\
\hline Pendiente Ministro 2 & 1 & 4 & 1 & 1 & 7 \\
Obsidiana negra & & 1 & & & 1 \\
Riolita & & 2 & & & 2 \\
Sílice & 1 & 1 & 1 & 1 & 4 \\
\hline Tapera Sandoval & & 1 & 1 & 4 & 6 \\
Dacita & & & 1 & 1 & 2 \\
Diorita & & & & 2 & 2 \\
Sílice & & 1 & & 1 & 2 \\
\hline Total general & 8 & 10 & 7 & 8 & 33 \\
\hline
\end{tabular}

variadas calidades. Las más abundantes son las rocas siliceas, que comprenden un $32 \%$ del total. Le sigue la dacita, con un $22,6 \%$ y la andesita y el basalto, ambos con un $12 \%$. También se observa la presencia de obsidiana negra, aunque se trata de una sola pieza. Al asociar materias primas con los productos de la secuencia de producción lítica, obtenemos que, tanto para los núcleos como para sus derivados, la materia prima más común es la dacita, mientras que en el caso de los productos terminados y los desechos de talla, es el sílice. Lo primero puede tener relación con la alta disponibilidad de dacitas de buena calidad disponibles naturalmente en el área.

En relación a la calidad de las rocas aprovechadas, más de la mitad del conjunto corresponde a calidades regulares, que incluyen andesitas, basaltos, dacitas, riolitas, sílices y tobas. Esta tendencia se repite en los productos de todos los segmentos de la secuencia de reducción, destacándose el caso de los derivados de núcleo. Las únicas piezas de rocas de muy buena calidad se concentran en la categoría de desechos.

Tanto en el caso de los productos terminados, como de los derivados de núcleo y desechos, la mayoría de las piezas (56\%) no presenta corteza, es decir, corresponden a lascas de desbaste secundario, $\mathrm{O}$ a artefactos cuya corteza ha sido removida mediante talla. Sólo en el caso de los núcleos, predominan $(50 \%)$ los que poseen un $25 \%$ de su superficie con corteza. En sólo 13 piezas, la corteza comprende más del $50 \%$ de su superficie.

El tamaño de las piezas oscila entre 1 y $16 \mathrm{~cm}$, con un $81 \%$ de ellas entre 2 y $7 \mathrm{~cm}$. Sólo 7 piezas $(6,9 \%)$ miden 10 o más $\mathrm{cm}$, de las cuales 5 corresponden a cepillos. Se observan algunas diferencias en relación a las categorías tecnológicas, lo cual puede tener implicancias significativas en cuanto a procesos de formación de sitios, ya que los objetos más grandes tienen menor capacidad de 


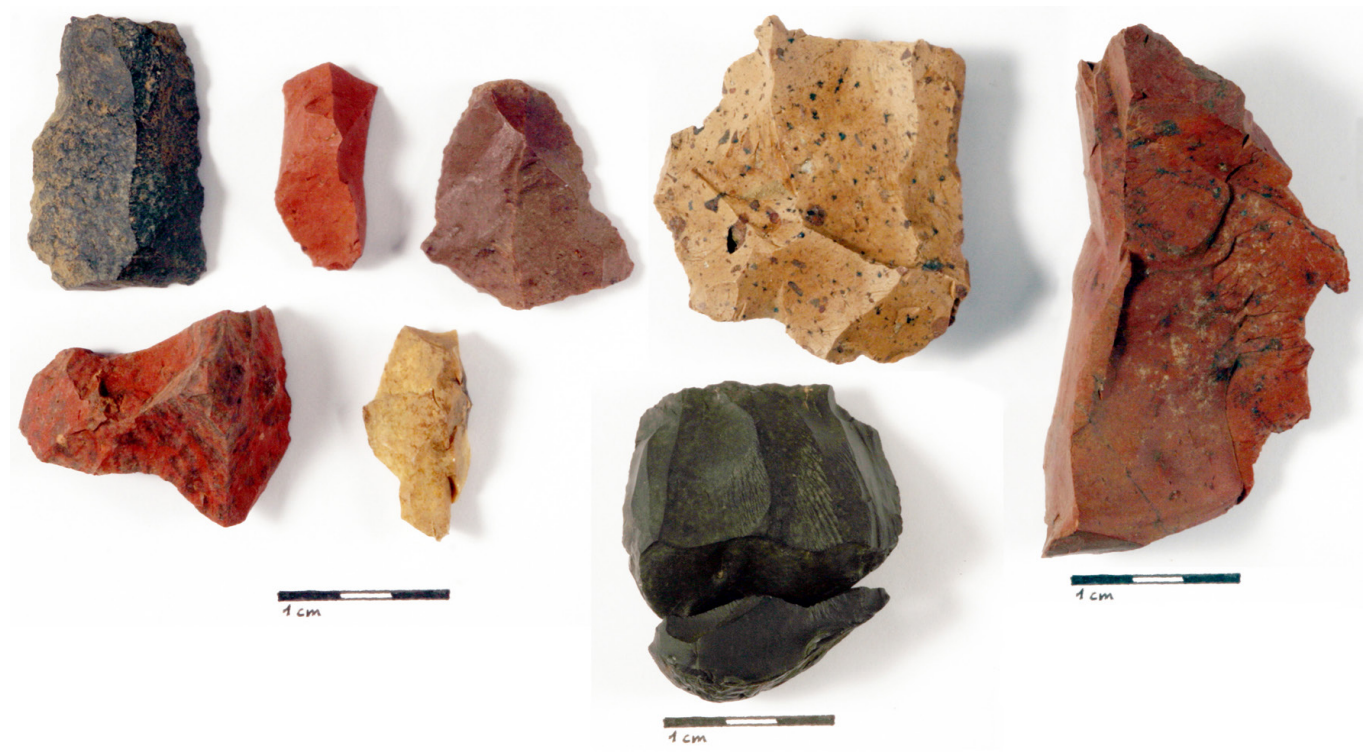

Fig. 3. Piezas provenientes del sitio La Frontera.

entierro y por ende tienen más posibilidades de ser recuperados en labores de prospección. Los desechos de talla se encuentran entre las piezas de menor tamaño, entre 1 y $6 \mathrm{~cm}$, mientras que los núcleos presentan tamaños intermedios, entre 5 y $9 \mathrm{~cm}$. Los productos terminados cubren todo el espectro, midiendo desde 2 a $16 \mathrm{~cm}$ y los derivados de núcleo fluctúan entre 2 y $10 \mathrm{~cm}$.

Para entender la arqueología de Alto Simpson a escala de sitio, nos concentraremos en aquellos que poseen más de cinco piezas completas. En este caso corresponden a cuatro: Tapera Sandoval (BAL 011; n=6), La Frontera (BAL 013; n=14), Aysén Sur (BAL 019; n=6) y Pendiente Ministro 2 (BAL 024; $n=7$ ), lo que suma una muestra de 33 piezas para estos sitios.

En el sitio Tapera Sandoval, la secuencia se encuentra incompleta, ya que están ausentes los derivados de núcleo. Destaca el hecho que los productos terminados son considerablemente más que los núcleos y desechos, cuando sería esperable que particularmente los desechos fueran más abundantes que los productos terminados, si se hubiera realizado un proceso de talla integral, lo cual viene a reafirmar el carácter fragmentario de la muestra. En el sitio La Frontera (Fig. 3) se encuentran evidencias de todas las fases de la secuencia de reducción lítica, aunque como hemos señalado anteriormente, no existen evidencias de la realización de cadenas operativas completas en ninguno de estos sitios. Sobresale la presencia de desechos de talla y núcleos. Aysén Sur, por su parte, también cuenta con un número preponderante de dacitas, que alcanzan el $66,6 \%$ del conjunto. En este sitio, sólo encontramos un núcleo y cinco derivados de núcleo, de los cuales tres coinciden en materia prima con el núcleo. Finalmente, en Pendiente Ministro 2 predominan los sílices, con un $57,1 \%$ y al igual que en La Frontera, se observan productos de todas las fases de la secuencia de reducción lítica. Aysén Sur es el único sitio que no presenta productos terminados, mientras que sólo Tapera Sandoval no incluye derivados de núcleo.

Existe una notable variabilidad en cuanto a las materias primas presentes en estos cuatro sitios, siendo el sílice la única que está presente en todos ellos. Otras como el basalto, la obsidiana negra y la toba, sólo existen en un sitio cada una. En general, la materia prima más abundante es la dacita y, cabe destacar, que La Frontera es el que presenta más diversidad, con 6 tipos distintos (andesita, basalto, dacita, riolita, sillice y toba).

Una característica relevante en el conjunto estudiado es la presencia de aristas paralelas en el anverso de los derivados de talla, sean estos desechos, derivados de núcleo o instrumentos, ya que pueden denotar una intencionalidad en la producción de láminas. En este caso, un $25,3 \%$ de las extracciones completas de Alto Simpson posee aristas paralelas. En relación 
Tabla 3. Categorías artefactuales halladas en los mayores sitios de Alto Simpson.

\begin{tabular}{cccc}
\hline Tecno-tipología & $\begin{array}{c}\text { Tapera } \\
\text { Sandoval }\end{array}$ & La Frontera & $\begin{array}{c}\text { Pendiente } \\
\text { Ministro 2 }\end{array}$ \\
\cline { 2 - 3 } Cepillo & 3 & \\
\cline { 2 - 3 } Lámina retocada \\
\cline { 2 - 3 } Lasca retocada \\
Raspador
\end{tabular}

a los productos de las distintas etapas de la secuencia de reducción lítica en estos sitios, las aristas paralelas están presentes en un $25 \%$ de los derivados de núcleo, un $10 \%$ de los desechos y lo que parece más relevante, un $42,8 \%$ de los productos terminados, aunque el número de piezas es demasiado bajo como para sugerir tendencias significativas. No obstante, sería necesario realizar un análisis detallado de este atributo antes de establecer con certeza la presencia de tecnología laminar en estos sitios.

\section{Categorías tecno-tipológicas presentes en las unidades}

Si bien la muestra arqueológica procedente de Alto Simpson es pequeña, su variabilidad tecno-tipológica registra trece categorías, incluyendo diversos tipos de desechos y de instrumentos, así como núcleos y derivados de núcleos (Fig. 4). Si revisamos las categorías tecnotipológicas representadas en los cuatro mayores sitios del sector, observamos que cada categoría artefactual está presente en un solo sitio (Tabla 3) y sólo la cuarta parte de los instrumentos hallados en Alto Simpson son formatizados $(\mathrm{N}=2)$. Sólo Tapera Sandoval presenta más de un tipo de instrumento (cepillos y un raspador), mientras que Aysén Sur no presenta ninguno. Por su parte, la presencia de instrumentos informales tales como lascas retocadas, puede dar cuenta del aprovechamiento de los filos vivos de los derivados de núcleo. Cabe mencionar que los dos instrumentos formales son de sílice. La muestra también incluye otros instrumentos procedentes de sitios menores o hallazgos aislados, que incluyen tres lascas y una lámina retocadas, dos cepillos, un bifaz de sílice y un cuchillo de andesita.

\section{Cadenas operativas y aprovechamiento de} materias primas líticas en Alto río Cisnes

A diferencia de lo observado en Alto Simpson, en el sector alto del valle del río Cisnes no sólo están presentes evidencias de todas las etapas de la secuencia de reducción lítica, sino que también se ha identificado cadenas operativas completas en algunas de las unidades estudiadas, es decir, evidencias que en algunas de ellas el descarte de los procesos de talla se encuentra mejor representado. De un total de 1.259 piezas constituyentes de esta muestra, 801 se encontraban completas, siendo consideradas para este análisis. Un 38,5\% de ellas corresponde a desechos de talla de diversos tipos, un $34,9 \%$ corresponden a derivados de núcleo, un $21,7 \%$ a productos terminados y un $4,7 \%$ a núcleos. En el valle del Cisnes, se ha encontrado evidencia del aprovechamiento de variados tipos de rocas, entre los cuales destaca el uso del sílice, el más abundante, representando el 67,04\% del total. La segunda roca más aprovechada es la andesita, con un $19,6 \%$. Cabe destacar también que sólo cinco de los 12 tipos de rocas identificados en el valle (andesita, rocas de grano grueso, obsidiana negra, sílice y toba) están presentes en todas las categorías de esta secuencia, es decir, incluyen núcleos, derivados de núcleo, desechos y productos terminados.

En cuanto a la calidad de estas materias primas, la mayor parte del conjunto (un 56,5\%) corresponde a rocas de buena calidad, mientras que un $24,8 \%$ son de calidad regular, un $11,3 \%$ son de muy buena calidad y un $7,1 \%$ son de baja calidad para la talla. Entre las materias primas de muy buena calidad están las piezas de obsidiana y algunas de sílice, mientras que en la categoría de rocas de buena calidad se destacan los sílices (Fig 5). Las rocas de calidad regular son más variadas, incluyendo ocho tipos de rocas, entre las cuales predominan variedades de andesitas. En relación a la presencia de corteza, observamos que la mayor parte del conjunto (un $77,1 \%$ ) no la exhibe.

En el conjunto arqueológico de Alto Cisnes predominan los derivados de talla, con un $91,7 \%$ del total (Tabla 4). Dentro del conjunto de los derivados de talla, se destacan los artefactos de sílice, que corresponden al 68,4\% y los de andesita, con un $19,8 \%$. Los artefactos de sílice también son muy 

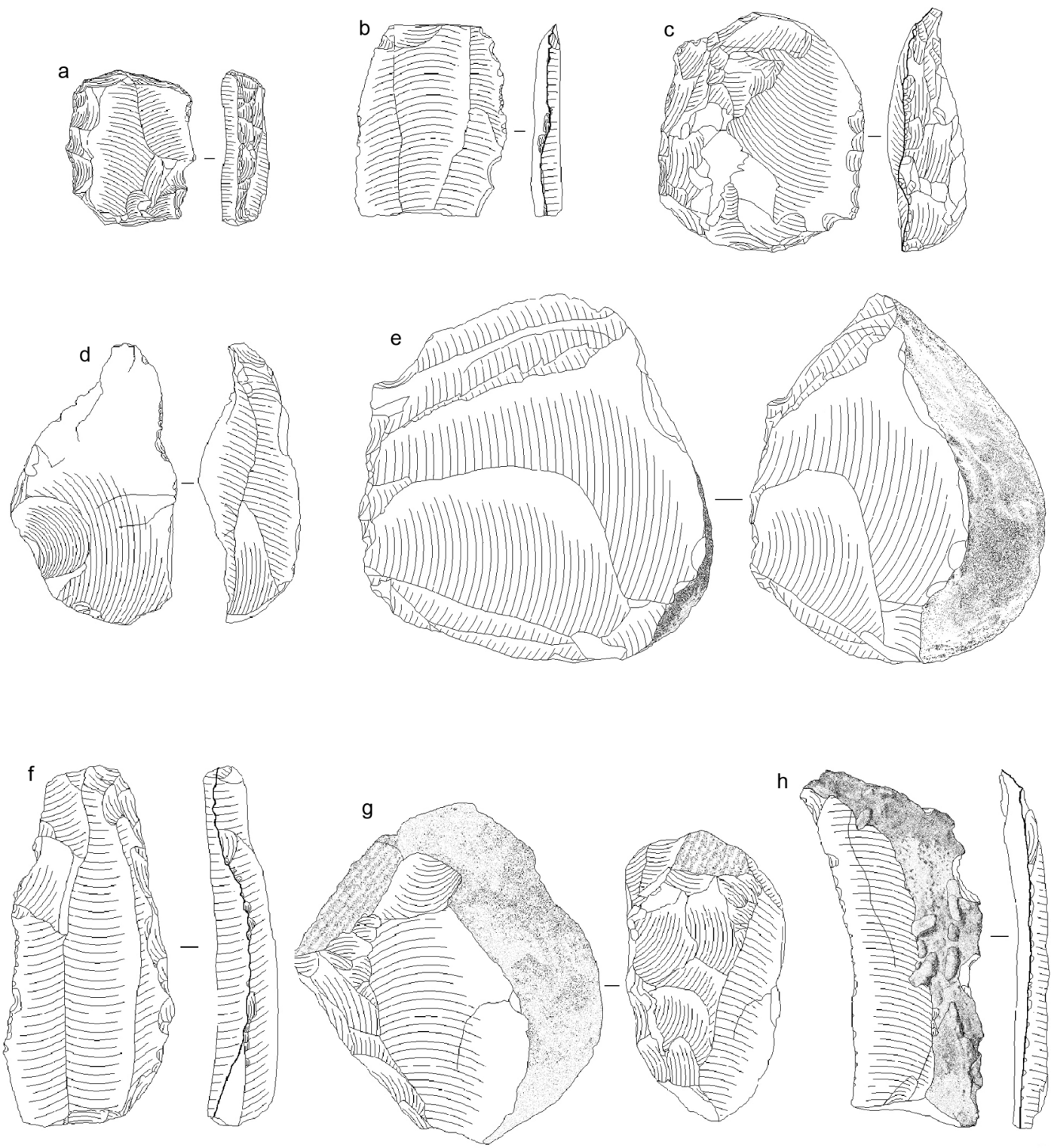

Fig. 4. Dibujos técnicos de algunas piezas de la muestra arqueológica de Alto Simpson. A: Raspador del sitio Pendiente Ministro 3. B: Lámina retocada del sitio Pendiente Ministro 2. C: Raspador del sitio Tapera Sandoval. D, E y G: Dos núcleos provenientes de La Frontera; las piezas D y G remontan. F: Raspador del sitio Irineo Valdez. H: Derivado de núcleo de Alero Ministro.

frecuentes entre los núcleos, alcanzando el 79,4\% en esta categoría. En relación a su aptitud para la talla, la mayor parte de los derivados de talla son de buena calidad (un 56,7\%), seguidos por los de calidad regular $(25,8 \%)$.

El tamaño de las piezas fluctúa entre 1 y $17 \mathrm{~cm}$. Un $86 \%$ mide entre 1 y $4 \mathrm{~cm}$, mientras que sólo 16 artefactos (el 1,2\%) miden 10 o más centímetros. Las piezas de mayor tamaño incluyen cepillos, derivados de núcleo, un lito discoidal, una mano de moler y un peso lítico, entre otros. Al igual que en Alto Simpson, se observan diferencias relativas al tamaño de las diferentes categorías tecnológicas. Los desechos muestran un menor 


\begin{tabular}{|c|c|c|c|c|c|}
\hline Materia Prima por Sitio & $\begin{array}{c}\text { Derivados de } \\
\text { núcleo }\end{array}$ & Desechos & Núcleos & $\begin{array}{l}\text { Productos } \\
\text { terminados }\end{array}$ & $\begin{array}{c}\text { Total } \\
\text { general }\end{array}$ \\
\hline Appeleg 1 Unidad 10 & 22 & 4 & 5 & 2 & 33 \\
\hline Andesita & 4 & 1 & & & 5 \\
\hline Diorita & 1 & & & & 1 \\
\hline MP grano grueso & 6 & & 1 & & 7 \\
\hline Obsidiana negra & & 1 & & & 1 \\
\hline Silice & 10 & 2 & 4 & 2 & 18 \\
\hline Toba & 1 & & & & 1 \\
\hline Appeleg 1 Unidad 16 & 7 & 3 & 1 & 4 & 15 \\
\hline Diorita & 1 & & & & 1 \\
\hline MP grano grueso & 1 & & & 2 & 3 \\
\hline Silice & 5 & 3 & 1 & 2 & 11 \\
\hline Appeleg 1 Unidad 20 & 11 & 23 & 4 & 12 & 50 \\
\hline Andesita & & 1 & & 1 & 2 \\
\hline Diorita & & 1 & & & 1 \\
\hline MP grano grueso & & & & 1 & 1 \\
\hline Silice & 10 & 21 & 4 & 9 & 44 \\
\hline Toba & 1 & & & 1 & 2 \\
\hline Appeleg 1 Unidad 21 & 33 & 19 & 1 & 17 & 70 \\
\hline Andesita & 13 & 4 & & 2 & 19 \\
\hline Basalto & 1 & 1 & & & 2 \\
\hline Diorita & & 1 & & 1 & 2 \\
\hline MP grano grueso & & 1 & & 1 & 2 \\
\hline Obsidiana negra & 1 & & & & 1 \\
\hline Sílice & 15 & 10 & 1 & 13 & 39 \\
\hline Toba & 3 & 2 & & & 5 \\
\hline Appeleg 1 Unidad 27 & 31 & 22 & 4 & 16 & 73 \\
\hline Andesita & 12 & 6 & & 3 & 21 \\
\hline Diorita & 1 & & & 1 & 2 \\
\hline MP grano grueso & & & & 1 & 1 \\
\hline Obsidiana negra & 1 & & & & 1 \\
\hline Silice & 17 & 16 & 4 & 11 & 48 \\
\hline Appeleg 1 Unidad 37 & 126 & 209 & 9 & 31 & 375 \\
\hline Andesita & 29 & 44 & 2 & 3 & 78 \\
\hline Basalto & 1 & 7 & & & 8 \\
\hline Diorita & 3 & 11 & & & 14 \\
\hline MP grano grueso & 1 & & & 1 & 2 \\
\hline Obsidiana negra & 2 & 1 & & 1 & 4 \\
\hline Silice & 87 & 143 & 7 & 23 & 260 \\
\hline Toba & 3 & 3 & & 3 & 9 \\
\hline Appeleg 2 & 22 & 22 & 7 & 18 & 69 \\
\hline Andesita & 2 & 5 & & 2 & 9 \\
\hline Basalto & 1 & 2 & & & 3 \\
\hline MP grano grueso & & 1 & & 1 & 2 \\
\hline Sílice & 19 & 14 & 6 & 15 & 54 \\
\hline Toba & & & 1 & & 1 \\
\hline El Deshielo & 15 & 3 & 6 & 41 & 65 \\
\hline Andesita & 8 & & & 12 & 20 \\
\hline Basalto & & & & 1 & 1 \\
\hline MP grano grueso & & & & 4 & 4 \\
\hline Obsidiana negra & 2 & 1 & 1 & 1 & 5 \\
\hline Sílice & 4 & 2 & 4 & 23 & 33 \\
\hline Toba & 1 & & 1 & & 2 \\
\hline Total general & 267 & 305 & 37 & 141 & 750 \\
\hline
\end{tabular}

Tabla 4. Segmento de la cadena operativa según materias primas, en los sitios de Alto Cisnes. Han sido excluidas las materias primas menos representadas, que corresponden a aquellas que presentan menos de 10 piezas (dacita, piedra pómez, riolita, vidrio riolítico y una roca volcánica indefinida).

tamaño, entre 1 y $6 \mathrm{~cm}$ (salvo una excepción de mayor tamaño). Los derivados de núcleo miden entre 1 y $9 \mathrm{~cm}$ (salvo dos excepciones), algo similar a lo que ocurre con los núcleos, de entre 2 y $10 \mathrm{~cm}$. Los productos terminados cubren todo el espectro de tamaños, entre 1 y $17 \mathrm{~cm}$.

Para un análisis más minucioso, se seleccionaron las unidades con más de cinco piezas completas, que para este sector corresponden a los siguientes: El Deshielo (65 piezas completas), Appeleg 1 unidad 10 $(\mathrm{N}=34)$, Appeleg 1 unidad $16(\mathrm{~N}=15)$, Appeleg 1 unidad 20 ( $\mathrm{N}=51)$, Appeleg 1 unidad 21 ( $\mathrm{N}=75)$, Appeleg 1 unidad 27 ( $\mathrm{N}=74)$, Appeleg 1 unidad 37 $(\mathrm{N}=380)$ y Appeleg $2(\mathrm{~N}=72)$. De este modo, la muestra total asciende a 766 piezas completas.

A partir de lo anterior, podemos señalar que en todos los sitios mencionados, la materia prima más representada es el sílice, seguido por la andesita. Las únicas excepciones son los casos de Appeleg 1 unidad 16, que no presenta andesita y unidad 20 , que tiene un bajo número. Además, en la mayoría de las unidades hay materias primas que están presentes con tan solo una pieza. La mayoría de las unidades muestra una variabilidad considerable de materias primas, particularmente las unidades 21 y 37, las que contabilizan once. La obsidiana se presenta de manera excepcional en Alto Cisnes, en El Deshielo $(\mathrm{N}=5)$ y Appeleg 1 unidad $37(\mathrm{~N}=4)$.

En relación a las cadenas operativas, observamos que en todas las unidades están presentes evidencias de cada una de las fases 


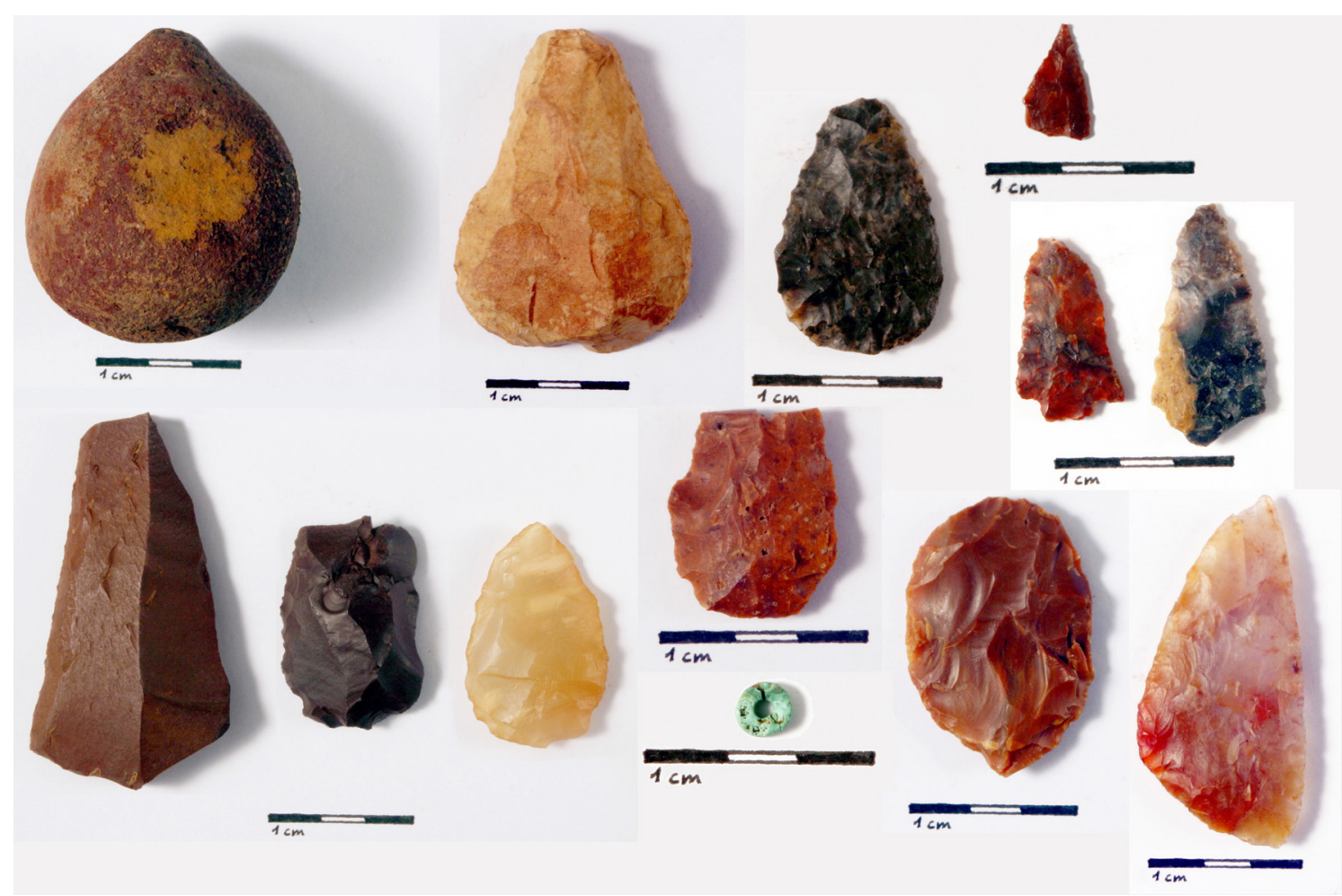

Fig. 5. Piezas provenientes de varias unidades del sitio Appeleg 1.

del proceso de reducción lítica, en mayor o menor medida. La proporción en la cual se presentan núcleos, derivados de núcleo, desechos y productos terminados, sin embargo, varía notablemente, destacando por ejemplo la abundante presencia de productos terminados en El Deshielo, la alta proporción en que se encuentran los derivados de núcleo en Appeleg 1 unidad 10, o los desechos en Appeleg 1 unidades 20 y 37. Esta variabilidad puede ser reflejo de diferencias en las actividades de talla que se realizaron en estos sitios. Esto sugiere que la acción de descarte de instrumental fue más acentuada en El Deshielo, mientras que en la unidad 10 de Appeleg 1 parece haber primado la extracción de lascas y, en cambio, en las unidades 20 y 37 de Appeleg 1 habrían sido preponderantes las fases de terminación y/o reavivado de instrumentos.

En relación a la presencia de aristas paralelas en el conjunto arqueológico de Alto Cisnes, observamos que el 47,5\% del total de 642 piezas tienen aristas paralelas. Si lo asociamos a los productos de las cadenas operativas, un $60,1 \%$ de los derivados de núcleo tiene esta característica, al igual que un $31,3 \%$ de los desechos y un $54,5 \%$ de los productos terminados, lo que consideramos porcentajes significativos, particularmente en el primer y el último caso. Esto sugiere que en gran parte del conjunto se destinó un esfuerzo en el diseño (sensu Andrefsky, 1994), que incluye la generación de núcleos formatizados destinados a la producción de láminas, lo que estaría implicando (entre otras características) un carácter más conservado para el conjunto de Alto Cisnes. Las categorías artefactuales que presentan aristas paralelas incluyen un cuchillo, láminas y lascas retocadas, una preforma, raederas y raspadores. $\mathrm{Si}$ realizamos este análisis unidad por unidad, encontramos que en cuatro de las ocho unidades el número de piezas que posee aristas paralelas supera al número que no las tiene $\mathrm{y}$, que incluso en los otros cuatro casos, el porcentaje de piezas con esta característica es considerable. No obstante $y$, tal como fue señalado para Alto Simpson, hace falta un análisis detallado de este atributo para 
Tabla 5. Categorías tecno-tipológicas, presentes en los sitios de Alto Cisnes.

\begin{tabular}{|c|c|c|c|c|c|c|c|c|c|}
\hline Tecno-tipología & $\begin{array}{l}\text { Appeleg } 1 \\
\text { Unidad } 10\end{array}$ & $\begin{array}{l}\text { Appeleg } \\
1 \text { Unidad } \\
16\end{array}$ & $\begin{array}{c}\text { Appeleg } \\
1 \text { Unidad } \\
20\end{array}$ & $\begin{array}{c}\text { Appeleg } \\
1 \text { Unidad } \\
21\end{array}$ & $\begin{array}{c}\text { Appeleg } \\
1 \text { Unidad } \\
27\end{array}$ & $\begin{array}{c}\text { Appeleg } \\
1 \text { Unidad } \\
37\end{array}$ & $\begin{array}{c}\text { Appeleg } \\
2\end{array}$ & $\begin{array}{c}\text { El } \\
\text { Deshielo }\end{array}$ & $\begin{array}{l}\text { Total } \\
\text { general }\end{array}$ \\
\hline Bifaz & 1 & & 1 & 1 & 1 & 1 & & & 5 \\
\hline Boleadora & & 1 & & & & & 1 & 3 & 5 \\
\hline Cepillo & & & & 2 & & & & 6 & 8 \\
\hline Cuchillo & & & & & 1 & 1 & & & 2 \\
\hline Cuenta & & 1 & & & & & & & 1 \\
\hline Lámina retocada & & & & 2 & & 1 & 4 & 8 & 15 \\
\hline Lasca retocada & & & 5 & 6 & 9 & 3 & 9 & 5 & 37 \\
\hline Lito discoidal & & & & & & 1 & & & 1 \\
\hline Machacador & & & & & & & & 1 & 1 \\
\hline Mano de moler & & & & & & & & 3 & 3 \\
\hline Núcleo retocado & & & & & & & & 1 & 1 \\
\hline Percutor & & & & & & 1 & & 1 & 2 \\
\hline Preforma & & & 1 & & 1 & & 1 & 1 & 4 \\
\hline Punta proyectil & & & & & & 4 & & & 4 \\
\hline Raedera & 1 & & & 1 & & 3 & & 1 & 6 \\
\hline Raspador & 1 & 1 & 3 & 3 & 3 & 17 & 4 & 11 & 43 \\
\hline Total general & 3 & 3 & 10 & 15 & 15 & 32 & 19 & 41 & 138 \\
\hline
\end{tabular}

caracterizar el uso de tecnología laminar en estos sectores.

\section{Categorías tecno-tipológicas presentes en las unidades}

El conjunto de artefactos arqueológicos hallados en Alto Cisnes (Fig. 6), incluye una amplia variabilidad tipológica y morfofuncional, la cual incluye veinte categorías diferentes. Estas consisten en bifaces, boleadoras, cepillos, cuchillos, cuentas, láminas y lascas retocadas, un lito discoidal, machacadores, manos de moler, percutores, preformas, puntas de proyectil, raederas y raspadores, como se muestra en la Tabla 5. En El Deshielo apreciamos una predominancia de raspadores y derivados de talla retocados, aunque existe una amplia variabilidad artefactual y funcional, mostrando la amplia gama de actividades que se llevaron a cabo en este lugar. En Appeleg 1, si consideramos todas las unidades, vemos que la gran mayoría de las categorías se ven representadas. De este sitio, podemos destacar que los cepillos se concentran en la unidad 21, a la vez que puntas de proyectil fueron halladas exclusivamente en la unidad 37. La unidad 37 de Appeleg 1 y el sitio El Deshielo son los que incluyen más tipos artefactuales. Del total de 133 instrumentos que incluye el conjunto, el $67,7 \%$ se considera formatizado.

\section{DISCUSIÓN}

Un factor relevante al comparar los dos valles es el evidente menor tamaño del conjunto de Alto Simpson, donde tan sólo se recuperaron setenta y cinco piezas completas, un número considerablemente menor a las 801 piezas de Alto Cisnes. El menor tamaño del conjunto de Alto Simpson conlleva a su vez una menor variabilidad en cuanto a materias primas empleadas, categorías tecno-tipológicas y, como parecen indicar nuestros resultados, actividades realizadas en los diversos sitios arqueológicos identificados en el sector. Esto puede ser reflejo de las características de la ocupación humana de este territorio, pero cabe la posibilidad que sea efecto del tamaño de la muestra. Futuros trabajos en el valle del río Simpson podrán ayudar a resolver esta problemática. 

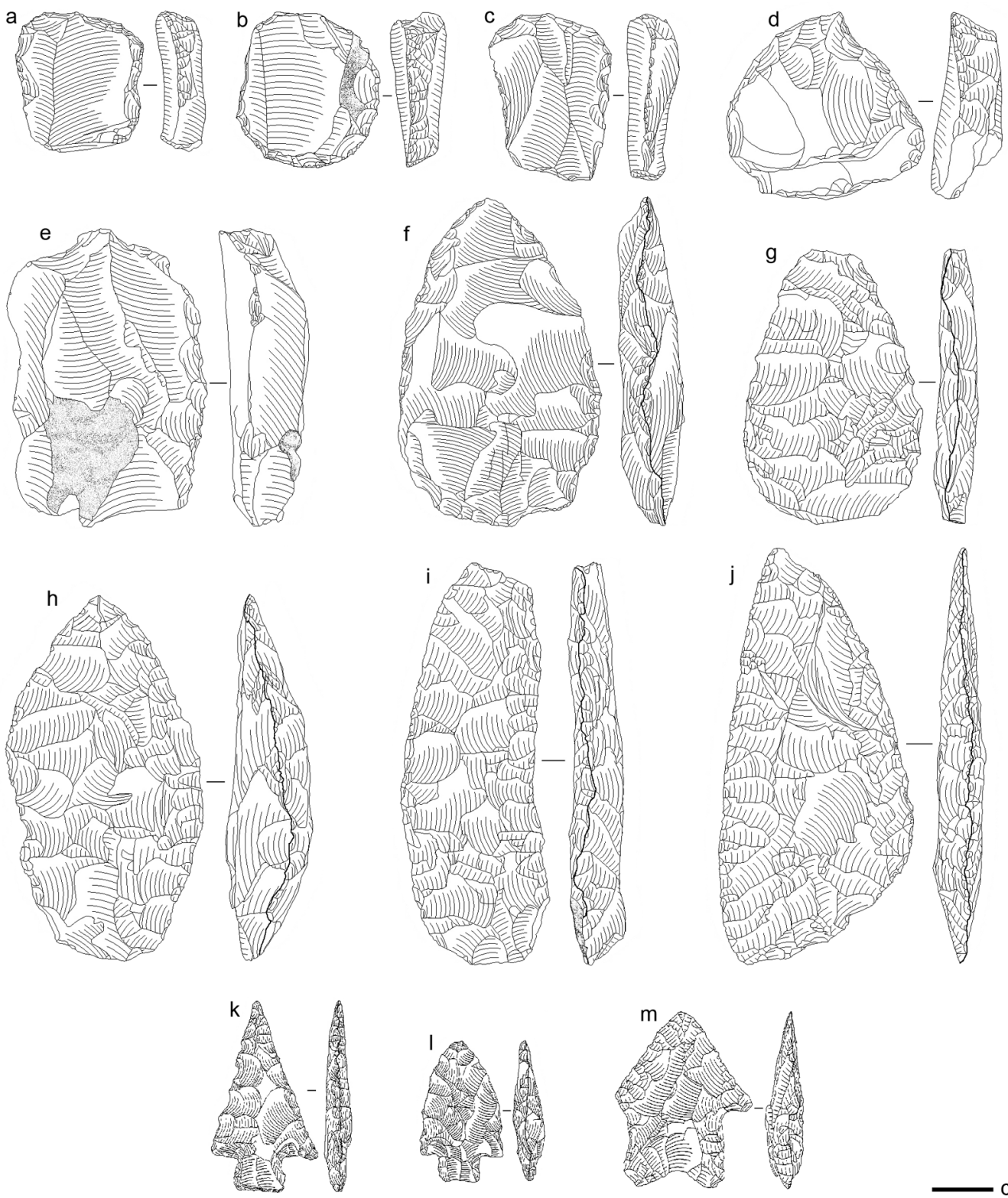

Fig. 6. Dibujos técnicos de algunas piezas de la muestra arqueológica de Alto Cisnes. A, C y D: Raspadores de Appeleg 1 u37. B: Raspador de Appeleg 1 sin unidad. E: Raspador de Appeleg 1 u10. F: Bifaz de Appeleg 1 u10. G: Punta de proyectil de Appeleg 1 u38. H: Bifaz de Appeleg 1 u36. I: Bifaz de Appeleg 1 u21. J: Cuchillo de Appeleg 1 s/u. K, L y M: Puntas de proyectil proveniente del sitio Appeleg 1 u37.

Tecnología de los conjuntos líticos de Aysén Centro Norte

Al evaluar comparativamente las características tecnológicas de ambos valles, vemos divergencias significativas. En primer lugar, sólo en Alto Cisnes se identificaron evidencias de cadenas operativas completas, que nos señalan que en las unidades arqueológicas allí ubicadas se llevaron a cabo secuencias donde una misma materia prima se trabajó desde las etapas iniciales de desbaste primario, hasta el retoque y reavivado de instrumentos. Este no es el caso de Alto Simpson, donde si bien se encuentran piezas 
correspondientes a todas las etapas de trabajo lítico, no existen cadenas operativas completas en ninguna unidad superficial o sitio muestreado.

Un factor que podría condicionar las posibilidades de hallazgo de unas de estas categorías por sobre otras es su tamaño, más aún al tratarse de sitios superficiales, emplazados en sectores que han sufrido disturbaciones formacionales importantes (principalmente Alto Simpson). Al respecto, cabe destacar que se observan similitudes entre ambos valles. El tamaño de los desechos, derivados de núcleo y productos terminados es muy similar en ambos casos y sólo se observa una diferencia entre los núcleos, que en Alto Cisnes incluyen tamaños más pequeños que aquellos recuperados en Alto Simpson. En términos formacionales, el menor tamaño de los desechos (y su consecuente mayor capacidad de entierro, Schiffer, 1996) pudo haber dificultado su recuperación durante los trabajos arqueológicos de prospección (Reyes et al. 2006). Sin embargo, la similitud entre los rangos de tamaño de ambos valles, sugiere que ambas muestras son comparables y que las proporciones en las que han sido recuperadas las diferentes categorías artefactuales puede hacer referencia a rasgos conductuales.

En Alto Simpson se observa una mayor proporción de núcleos y de productos terminados, mientras que Alto Cisnes posee más desechos y derivados de núcleo, lo que sugiere que en este último sector se realizó un número considerablemente mayor de episodios de talla. Esto puede responder al carácter residencial que se postula para sus tres sitios principales (Appeleg 1, Appeleg 2 y El Deshielo, ver Velázquez et al. 2007), ya que la longitud de ocupación habría generado una mayor disponibilidad para la manufactura y reparación de su conjunto artefactual (Binford, 1979; Nelson 1991). En cuanto a los derivados de talla, notamos que en Alto Cisnes la presencia de aristas paralelas es bastante más usual que en Alto Simpson, llegando a constituir casi el $50 \%$ del conjunto, mientras que en Alto Simpson alcanza la cuarta parte. Esto refleja el uso de núcleos formatizados y un interés particular en la producción de láminas, lo que significa una mayor inversión de tiempo y esfuerzo en la actividad de tallar. La técnica de extracción también es un criterio relevante de comparación entre ambos valles, ya que mientras que en Alto
Cisnes la técnica más empleada fue la percusión blanda (75,9\%), en Alto Simpson corresponde a la percusión dura, que cuenta con un $72 \%$.

Los instrumentos que integran la muestra de Alto Cisnes presentan un alto grado de formatización (67,7\%), mientras que en Alto Simpson sólo la cuarta parte del conjunto tiene carácter formal. En el caso de los instrumentos de corte, en ambos valles se observa que un número significativo de ellos es informal, lo cual tiene relación con el aprovechamiento de los filos vivos de los derivados de núcleo. En relación a la presencia de instrumentos formales de Alto Cisnes, cabe mencionar que, como señala Binford (1979), el descarte del instrumental relacionado con el desgaste natural de un instrumento era realizado generalmente dentro del campamento residencial y no en el campo donde tenía lugar la actividad en la que tal instrumento sería utilizado. Esto podría ser un argumento a favor de la existencia de campamentos residenciales en este sector.

A modo de síntesis, podemos decir que el sector de Alto Cisnes incluye contextos de gran tamaño y mayor complejidad, particularmente en el caso de los sitios El Deshielo y Appeleg 1. En cambio, la muestra de Alto Simpson es muy pequeña y de naturaleza fragmentaria. Se observa un registro incompleto (por ejemplo en relación a las cadenas operativas), e inconsistente con el dominio de alguna actividad de procesamiento lítico, el cual además presenta un número excepcionalmente bajo de piezas. El conjunto de Alto Cisnes es significativamente más formatizado que el de Alto Simpson, en todas sus categorías tecno-tipológicas y se observa que se dedicó una mayor cantidad de tiempo y trabajo a su realización y mantención. El conjunto de Alto Simpson, en cambio, es en mayor medida informal, salvo por un bajo número de piezas cuyo diseño mostró mayor elaboración. Estas características, sumadas a las entregadas en el acápite anterior relativas al aprovechamiento y tratamiento de las materias primas, nos permite atribuir a cada uno de estos valles una estrategia tecnológica diferente, mayormente expeditiva en Alto Simpson y conservada en Alto Cisnes, ya que en el primer caso nos enfrentamos a un conjunto que denota un mínimo esfuerzo tecnológico en su producción, lo cual, siguiendo a Nelson (1991), puede sugerir que este espacio 
fue en el pasado considerado como una fuente de recursos líticos altamente predecibles y favorables a las necesidades del grupo social. En el segundo caso, en cambio, observamos la preparación por adelantado de las materias primas y que atributos tales como la maximización de la vida útil, los diseños elaborados y conductas de reciclaje juegan un rol sustantivo (Shott, 1996), lo cual puede reflejar la anticipación de una ausencia de materias primas de calidad y/o la existencia de condiciones desfavorables para la preparación de instrumentos (Nelson, 1991). No obstante lo anterior, en ambos valles se aprovecharon recursos locales como parte de una estrategia oportunista, particularmente en relación al aprovechamiento de materias primas de calidades regular y baja para la talla.

En relación a la vida útil de los artefactos dentro de estas categorías, esta característica también puede denotar una diferencia entre ambos sectores de estudio. Si la formatización de los instrumentos tiene como una de sus consecuencias la maximización de su vida útil $y$, en cambio, los instrumentos informales usualmente son manufacturados, utilizados y descartados en un periodo de tiempo relativamente corto (Andrefsky, 1994, p. 22), es significativo que el conjunto de Alto Cisnes presente una mayor cantidad de piezas y una proporción mayor de instrumentos formatizados, mientras que el conjunto de Alto Simpson, además de ser reducido en número, presenta una mayoría de instrumentos informales. Esto parece sostener la existencia de ocupaciones no sólo reiteradas, sino también de mayor duración en Alto Cisnes $y$ de ocupaciones breves en Alto Simpson. Esta noción es fortalecida por otras características, tales como el hecho que no se hayan observado sitios residenciales en Alto Simpson.

Función de los conjuntos materiales de Aysén Centro Norte

El sector de Alto Cisnes incluye tres grandes conjuntos de variada complejidad y tamaño. En El Deshielo predominan los productos terminados, seguidos de los derivados de núcleo, los núcleos y un número reducido de desechos. Dentro de la primera categoría, observamos que los instrumentos se pueden agrupar en seis categorías morfofuncionales diferentes, lo que nos habla de la realización de un importante número de actividades en el sitio, que incluyen la caza, el corte, la molienda, el procesamiento de cueros y maderas y la talla lítica. Esto sugiere una función residencial para El Deshielo, con una orientación al abastecimiento y trabajo de la madera, acorde a su significativa proporción de cepillos. Al respecto cabe mencionar que, al menos en la actualidad, el sitio se emplaza inmediatamente adyacente a un sector boscoso.

Appeleg 1 corresponde a la unidad de mayor ocurrencia de registro arqueológico del valle. Al igual que $\mathrm{El}$ Deshielo, presenta una gran variabilidad artefactual y de categorías funcionales, aunque se distingue de aquel sitio por su carácter multicomponente. Si consideramos Appeleg 1 como un todo, podemos afirmar que en el sitio se realizaron actividades de caza, corte, procesamiento de cueros y maderas, producción de líticos y se observan además instrumentos multifuncionales. En el sitio se hallaron también instrumentos de molienda, los cuales, sin embargo, fueron registrados en terreno. Incluye implementos de uso doméstico, que sostienen la realización de actividades propias de sitios residenciales. Además, si consideramos las distintas unidades de Appeleg 1 , vemos que las categorías funcionales difieren considerablemente entre una y otra. Este hecho, sumado a la evidencia que sugiere que el sitio sufrió procesos de coadunación de distintas ocupaciones y que fue utilizado en variadas ocasiones, nos sugiere que Appeleg 1 pudo haber tenido más de una función a través del tiempo.

Por su parte, el sitio Appeleg 2 ha sido descrito como un campamento residencial de uso breve, lo cual es coherente con nuestros resultados. En este lugar se encontró evidencias de la realización de actividades de caza, corte, procesamiento de cuero y producción de líticos, que se condicen con prácticas domésticas (el instrumental de caza representaría el descarte de instrumentos, en un contexto de preparación y reparación del artefactual empleado en labores realizadas en otros sectores). No están presentes, sin embargo, instrumentos de molienda.

En Alto Simpson nos encontramos con una realidad muy diferente, debido al reducido tamaño del conjunto y su carácter fragmentario. Por estas razones no es posible determinar funciones 
discretas para estos sitios. Podemos, sin embargo, al menos sugerir una serie de actividades que se llevaron a cabo en este valle. De esta manera, podemos establecer que de los cuatro sitios que cuentan con un mínimo de cinco piezas completas, Aysén Sur es el único que no incluye instrumentos El sitio Tapera Sandoval presenta características muy distintas, ya que además de contar con un núcleo, incluye cuatro instrumentos destinados a labores específicas, como son tres cepillos, que sugieren una orientación hacia la explotación de recursos de bosque. A su vez, el sitio Pendiente Ministro 2 muestra una predominancia de la actividad de talla lítica. El último sitio es La Frontera, el cual si bien cuenta con una mayor cantidad de piezas $(n=14)$, describe la realización de tan sólo dos actividades que corresponden a la talla de lítica y labores de corte, como lo sugieren láminas retocadas.

Uso del espacio en Aysén centro Norte: diversidad y tendencias del registro espacial

Las características de la muestra arqueológica de Alto Simpson han llevado a que sea considerado como un espacio vacio (Méndez et al. 2011b). Al menos dos factores son relevantes: las características de las ocupaciones humanas que se llevaron a cabo en este lugar y procesos de formación de sitios que pueden haber contribuido a dificultar la visibilidad de los restos de tales ocupaciones. En relación a lo segundo, Alto Simpson presenta en la actualidad un ecosistema de estepa, donde los sectores de bosque se limitan a parches de reducido tamaño. Sin embargo, la gran intensidad de incendios forestales históricos en esta zona sugiere una diferente distribución de la cobertura del bosque antes de esta época (Méndez et al. 2013). Si asumimos un ambiente más cerrado, debiéramos esperar incursiones más limitadas y condicionadas a cursos de movilidad naturales (Méndez et al. 2011c), como ha sido propuesto, con algunas diferencias, para los sectores de Traful (en Neuquén), Cholila y Los Alerces (en Chubut).

Para estos espacios, se ha sugerido que la ocupación de los bosques pudo haber ocurrido en el marco de circuitos de movilidad más amplios, que también incluían la estepa y zonas de transición bosque-estepa (Arrigoni, 1997; Bellelli et al. 2003; Silveira, 1999).
Una posible respuesta se encuentra en las condiciones climáticas que afectaron la zona durante el Holoceno Tardío. Entre los años 4.200 y 2.900 años AP se presentaron condiciones más secas (Markgraf et al. 2007), que pudieron ocasionar una redistribución y disminución de los recursos de la estepa, fomentando una reorganización de la movilidad tanto hacia el oriente como el occidente, en búsqueda de condiciones más favorables (Méndez \& Reyes, 2008; Reyes et al. 2009). En el valle del río Cisnes, la presencia humana estuvo limitada a la estepa hasta los 2.800 años AP, momento en el cual comenzaron una serie de incursiones hacia los bosques, visitas estacionales reiteradas aunque breves, por parte de las mismas poblaciones (Méndez \& Reyes, 2008; Reyes et al. 2009). De esta manera, tenemos que los sectores de estepa se ocuparon en fechas mucho más tempranas que los bosques y llegado el Holoceno Medio, ambos espacios fueron aprovechados de forma contemporánea, como prueban las ocupaciones fechadas en los sitios El Chueco, Las Quemas y El Toro, ubicados respectivamente en la estepa, un sector de transición bosque-estepa y el bosque siempreverde (Méndez \& Reyes, 2008). Esto se traduce en una ampliación de los rangos de movilidad y el aprovechamiento de nuevos espacios más allá de la estepa, que al menos en el valle del Cisnes acontecieron entre los $\sim 2.650$ y 2.350 años cal. AP. Todo esto guarda similitudes con lo que Borrero (2004) sugiere como la ocupación de espacios marginalmente ocupados desde núcleos poblacionales más al oriente. De todos modos, los asentamientos en la estepa continuaron siendo predominantes en los valles andinos de Aysén (Mena, 2000; Mena \& Lucero, 2004, Méndez \& Velásquez, 2005; Reyes et al. 2009).

Dentro de este contexto, tanto Alto Simpson, que correspondería a un espacio boscoso, como Alto Cisnes, que pertenece a la estepa abierta, parecen haber sido ocupados estacionalmente durante al menos parte del Holoceno Tardío, Alto Cisnes durante la temporada estival (como lo sugiere la información faunística y botánica de El Chueco, Méndez et al. 2011a) y Alto Simpson (si bien no se cuenta con datos) posiblemente durante el invierno, cuando las condiciones en la estepa se tornaban muy duras para la habitabilidad. En el valle del río Simpson, a diferencia del río Cisnes, no se ha 
descubierto evidencias que permitan establecer qué espacios pudieron haber sido ocupados el resto del año. Al respecto, Méndez et al. (2011b) postulan que posiblemente, estas ocupaciones se ubican en esa latitud en territorio argentino, en función de los hallazgos de Pérez de Micou et al. (2010, 2013). El bajo número de sitios respondería a que el área fue utilizada como parte de incursiones de baja intensidad desde las estepas orientales al bosque. Alto Simpson sería entonces comparable al área del Cisnes Medio (sitios Winchester 1 y 2 y Alero Las Quemas), que cuentan con fechas posteriores a los 2.700 años cal. AP y una menor cantidad de sitios respecto de lo que sucede en la estepa (Méndez et al. 2011b, p. 6).

\section{CONCLUSIÓN}

Los conjuntos arqueológicos provenientes de estos dos sectores son altamente contrastantes entre sí, siendo aquel correspondiente a Alto Cisnes más abundante y variado funcionalmente. Las materias primas aprovechadas son de buena calidad y en un alto porcentaje, serían alóctonas. El mayor sitio, Appeleg 1, es de carácter multicomponente y fue ocupado desde fechas tempranas. En el caso de Alto Simpson, los sitios arqueológicos son muy pequeños y de naturaleza fragmentaria y los recursos líticos aprovechados son en su gran mayoría locales y de calidad regular. En estos sitios se encontró evidencia de un reducido número de actividades y parecen corresponder a un único momento ocupacional en todos los casos.

Como hemos señalado a lo largo de este trabajo, en la actualidad los sectores altos de estos valles presentan similitudes geográficas, climáticas y de recursos disponibles, lo cual contrasta con las diferencias sustanciales que se observan en relación a la ocupación prehistórica de ambos valles. Los factores ambientales que dieron su distinta fisonomía a cada sector, generando condiciones esteparias o boscosas en ellos, sumados a procesos postdepositacionales, pueden dar luces acerca de tales divergencias. Por estas razones, resulta interesante replicar a futuro esta clase de investigación comparativa en otros valles de la región, buscando en el registro arqueológico evidencias de la variabilidad humana para aproximarse a ambientes que en la actualidad se perciben como similares.

\section{AGRADECIMIENTOS}

Investigación financiada por el proyecto FONDECYT 1130128. Se desea agradecer a la comunidad de Galera, a Cirilo Peede y Estancia La Frontera, a Stephanie Bouckaert, Eduardo Batarce y Estancia Río Cisnes. Agradecemos a todos quienes apoyaron en las labores de terreno y gabinete: Ramiro Barberena, Carolina Belmar, Luis Borrero, Pedro Cárdenas, Paulina Chávez, Pablo González, Rodrigo Loyola, Antonio Maldonado, Fabiana Martin, Ismael Martínez, Francisco Mena, Amalia Nuevo Delaunay, Cristina Ortega, Mauricio Osorio, María Eugenia de Porras, Claudia Quemada, Manuel San Román, Fernando Sepúlveda, Charles Stern, Valentina Trejo, Héctor Velásquez, Cynthia Zielhmann y Leonardo Zúñiga.

\section{BIBLIOGRAFÍA}

Andrefsky, W. (1994). Raw-material availability and the organization of technology. American Antiquity, 59(1), 21-34.

Andrefsky, W. (1998). Lithics. Macroscopic approaches to analysis. Cambridge: Cambridge University Press.

Arrigoni, G. I. (1997). Pintando entre lagos y bosques (las pinturas rupestres del Parque Nacional Los Alerces. Chubut). Actas y Memorias del XI Congreso Nacional de Arqueología Argentina (Cuarta Parte). Revista del Museo de Historia Natural de San Rafael (Mendoza), Tomo XVI (1/4), 241-268.

Aschero, C. (1983 [1975]). Ensayo para una clasificación morfológica de artefactos líticos. Manuscrito. Buenos Aires.

Bellelli, C., Carballido, M., Fernández, P., \& Scheinsohn, V. (2003). El pasado entre las hojas. Nueva información arqueológica del noroeste de la provincia de Chubut, Argentina. Werken, 4, 25-42.

Binford, L. (1979). Organization and formation processes: looking at curated technologies. Journal of Anthropological Research, 35(3), 255-273.

Borrero, L. A. (1994-95). Arqueología de la Patagonia. Palimpsesto, Revista de Arqueología, 4, 9-69.

Borrero, L. A. (2004). The Archaeozoology of Andean 'Dead Ends' in Patagonia: Living near the Continental Ice Cap. En M Mondini, S. Muñoz \& S. Wickler (Eds.), Colonisation, Migration and Marginal Areas. A 
Zooarchaeological approach (pp. 55-61). Oxbow Books, Oakville.

De Porras M. E., Maldonado, A., Abarzúa, A., Cárdenas, M., Francois, J. P., Martel-Cea, J. A., Stern, Ch.,...Reyes, O. (2012). Postglacial vegetation, fire and climate dynamics at Central Chilean Patagonia (Lake Shaman, $44^{\circ}$ S). Quaternary Science Reviews, 50, 71-85.

De Porras M. E., Maldonado, A., Abarzúa, A., Cárdenas, M., Francois, J. P., Martel-Cea, J. A., Stern, Ch.,... Reyes, O. (2014). Environmental and climatic changes in Central Chilean Patagonia since the Late Glacial (Mallin El Embudo, $\left.44^{\circ} \mathrm{S}\right)$. Climate of the Past, 9(5), 5747-5784.

Garreaud, R. (2009). The Andes climate and weather. Advances in Geosciences, 22, 3-11.

Jackson, D. (2002). Los instrumentos líticos de los primeros cazadores de Tierra del Fuego. Santiago: DIBAM.

Jackson, D., \& Méndez, C. (2007). Litos discoidales tempranos en contextos de Patagonia. Magallania, 35(1), 75-84.

Luebert, F. \& Pliscoff, P. (2006). Sinopsis bioclimática y vegetacional de Chile. Santiago: Editorial Universitaria.

Markgraf, V., Whitlock, C., \& Haberle, S. (2007). Vegetation and fire history during the last 18,000 cal yr B.P. in Southern Patagonia: Mallín Pollux, Coyhaique, Province Aisén (4541'30' S, 7150'30” W, 640 $\mathrm{m}$ elevation). Palaeogeography, Palaeoclimatology, Palaeoecology, 254, 492-507.

Martinic, M. (2005). De la Trapananda al Aysén: una mirada reflexiva sobre el acontecer de la Región de Aysén desde la prehistoria hasta nuestros días, Pehuén, Santiago.

Mena, F. (2000). Un panorama de la prehistoria de Aisén Oriental; estado de conocimiento a fines de siglo. Serie Antropología, 2, 21-41.

Mena, F., \& Lucero, V. (2004). En torno a las últimas poblaciones indígenas de la cordillera centro-patagónica: estudio comparado de tres valles en Aisén oriental (Chile). En M. Civalero, P. Fernández \& G. Guráieb (Eds.), Contra viento y marea. Arqueología de Patagonia, (pp. 643657). Buenos Aires: INAPL.

Mena, F., \& Stafford, T. (2006). Contexto estratigráfico y fechación directa de esqueletos humanos del Holoceno temprano en Cueva Baño Nuevo 1 (Patagonia Central, Chile). En J. Jiménez, S. González, J. Pompa \& F. Ortíz (Eds.), Segundo Simposio Internacional del Hombre Temprano en América (pp. 139-54). Ciudad de México: INAH.

Méndez, C., \& Velázquez, H. (2005). Tecnología y subsistencia en Alero Entrada Baker: una revisión a la luz de nuevos antecedentes. Actas del XVI Congreso Nacional de
Arqueología Chilena, Tomo I (pp. 593-602). Tomé: Museo de Historia Natural de Concepción.

Méndez, C., \& Reyes, O. (2008). Late Holocene human occupation of Patagonian forests: a case study at Cisnes River basin (44 S, Chile). Antiquity, 82, 560-570.

Méndez, C., Reyes, O., \& Velásquez, H. (2006). Tecnología lítica en el alto río Cisnes (estepa extra andina de la XI Región de Aisén): primeros resultados. Boletín de la Sociedad Chilena de Arqueología, 39, 87-101.

Méndez, C., Reyes, O., Nuevo Delaunay, A., Trejo, V., Barberena, R., \& Velásquez, H. (2011a). Ocupaciones humanas en la margen occidental de Patagonia Central: eventos de poblamiento en Alto río Cisnes. Magallania, 39, 223-242.

Méndez, C., Reyes, O., \& Mena, F. (2011b). Segundo informe de avance. FONDECYT 1090027. Santiago.

Méndez, C., Reyes, O., Trejo, V.. \& Nuevo Delaunay, A. (2011c). Ocupación humana de la margen occidental de la estepa de Patagonia Central: el área de Balmaceda (Aisén) como caso de estudio para medir la intensidad de (des)uso de espacios. Presentación en las VIII Jornadas de Arqueología de la Patagonia. Malargüe.

Méndez, C., Reyes, O., Trejo V., \& Nuevo Delaunay, A. (2013). Ocupación humana de alto río Simpson, Aisén (margen occidental de la estepa de Patagonia Central) como caso para medir la intensidad de uso de espacios. En A. F. Zangrando, R. Barberena, A. Gil, G. Neme, M. Giardina, L. Luna, C. Otaola, S. Paulides, Ñ- Salgán \& A. Tivoli (Eds.), Tendencias teóricometodológicas y casos de estudio en la arqueología de la Patagonia (pp. 193-201). Buenos Aires: Museo de Historia Natural de San Rafael-Sociedad Argentina de Antropología-Instituto Nacional de Antropología y Pensamiento Latinoamericano.

Nelson, M. (1991). The study of technological organization. En M. Schiffer (Ed.), Archaeological Method and Theory Vol. 3 (pp. 57-100). University of Arizona Press.

Odell, G. (2003). Lithic Analysis. Manuals in Archaeological Method, Theory \& Technique. New York: Springer Science \& Business Media Inc.

Pérez de Micou, C., Trivi de Mandri, M., \& Burry, L. S. (2010). Imágenes desde un alero. Investigaciones multidisciplinarias en Río Mayo. Buenos Aires.

Pérez de Micou, C., Castro Esnal, A. \& Sacchi, M. (2013). Estudios preliminares en el sitio Casa de Piedra, Estancia Roselló, sudoeste de Chubut. En A. F. Zangrando, R. Barberena, A. Gil, G. Neme, M. Giardina, L. Luna, C. Otaola, S. Paulides, Ñ- Salgán \& A. Tivoli (Eds.), 
Tendencias teórico-metodológicas y casos de estudio en la arqueología de la Patagonia (pp. 213-218). Buenos Aires: Museo de Historia Natural de San RafaelSociedad Argentina de Antropología-Instituto Nacional de Antropología y Pensamiento Latinoamericano.

Prieto, X., Cortes, J., \& Suárez, M. (1994). Mapa Geológico del área oriental de la Hoja Puerto Cisnes. Región Aisén del General Carlos Ibáñez del Campo. (Versión preliminar). Santiago: SERNAGEOMIN.

Quintanilla, V. (1983). Biogeografía. Geografía de Chile, Tomo III. Santiago: Instituto Geográfico Militar.

Reyes, O., Méndez, C., Velásquez, H., \& Trejo, V. (2006). Distribuciones espaciales y contextos arqueológicos de cazadores recolectores esteparios en Alto río Cisnes (XI Región de Aisén). Magallania, 34(2), 75-90.

Reyes, O., Méndez, C., Trejo, V., \& Velásquez, H. (2007). Ocupaciones humanas tardías en la transición bosque estepa: La localidad de Winchester (curso alto del rio Cisnes, XI Región de Aisén). Magallania, 35(2), 145150.

Reyes, O., Méndez, C., Maldonado, A., Velásquez, H., Trejo, V., Cárdenas, M., \& Abarzúa, A. (2009). Uso del espacio de cazadores recolectores y paleoambiente Holoceno en el valle del río Cisnes, Región de Aisén, Chile. Magallania, 37(2), 91-107.

Reyes, O., Méndez, C., Mena, F., \& Moraga, M. (2012). The bioanthropological evidence of a ca. 10,000 CALYBP ten-individual group in Central Patagonia. En L. Miotti, M. Salemme, N. Flegenheimer \& T. Goebel (Eds.),
Southbound: Late Pleistocene peopling of Latin America (pp. 39-43). Oregon: Center for the Study of the First Americans, College Station.

SERPLAC. (2005). Atlas de la Región de Aysén. Santiago: Ministerio de Planificación y Cooperación, LOM Ediciones.

Schiffer, M. (1996). Formation processes of the archaeological record. University of Utah Press, Salt Lake City.

Shott, M. (1996). An exegesis of the curation concept. Journal of Anthropological Research, 52(3), 259-280.

Silveira, M. (1999). El alero Lariviére: un sitio en el bosque septentrional andino. En J. Belardi, P. Fernández, R. Goñi, A. Guráieb \& M. De Nigris (Eds.), Soplando en el Viento, Actas de las III Jornadas de Arqueología de la Patagonia (pp. 83-99). Buenos Aires: Instituto Nacional de Antropología y Pensamiento Latinoamericano.

Silveira, M. (1999). Alero Cicuta (Departamento Los Lagos, Provincia del Neuquén, Argentina). En J. Belardi, P. Fernández, R. Goñi, A. Guráieb \& M. DeNigris (Eds.), Soplando en el Viento, Actas de las III Jornadas de Arqueología de la Patagonia (pp. 561-576). Buenos Aires: Instituto Nacional de Antropología y Pensamiento Latinoamericano.

Velásquez, H., Méndez, C., Reyes, O., Trejo, V., Sanhueza, L., Quiroz, D., \& Jackson, D. (2007). Campamentos residenciales tardíos a cielo abierto en el alto rio Cisnes (XI Región de Aisén): Appeleg 1 (CIS 009). Magallania, 35(1), 85-98. 
